\title{
ПРОБЛЕМЫ ФУНКЦИОНИРОВАНИЯ ЦЕПОЧКИ «ОБРАЗОВАНИЕ-НАУКА-ИННОВАЦИИ»
}

\author{
(c) 2020 Самсонова Марина Владимировна \\ кандидат экономических наук, доцент \\ Оренбургский государственный университет, Россия, Оренбург \\ E-mail: sammar@rambler.ru
}

В статье показано, что эффективная, слаженная работа цепочки «образование-наукаинновации» - это один из инструментов экономического роста экономики в целом. Смещение акцентов на новые знания, позволяющие создавать инновации и воплощаемые в технологиях, оборудовании и других продуктах, требует качественного образования, которое, в свою очередь дает толчок развитию науки.

Ключевые слова: образование, наука, инновации, экономика знаний.

Закономерность общественного развития последних лет - переход к экономике, основанной на знаниях, отличительной чертой которой является ускоренное развитие нематериальной сферы хозяйственной деятельности. В экономике знаний университеты понимаются как инструменты экономического роста, и широко известным становится тот факт, что на долю новых знаний, воплощаемых в технологиях, оборудовании, подготовке кадров, организации производства, в экономически развитых странах приходится от 70 до 85\% прироста валового внутреннего продукта (ВВП) [1]. В этом аспекте становятся актуальными и необходимыми взаимодействие таких сфер деятельности как «образование-наука-инновации».

В исторической ретроспективе доказано, что именно образование дает толчок развитию науки. В основе этого утверждения лежит тот непреложный факт, что именно система образования (сначала средняя школа, затем высшая) обеспечивает подготовку специалистов, способных совершить необходимый стране технологический рывок.

Наука же призвана обеспечивать получение новых знаний, которые в свою очередь позво- лят создавать инновации. Для инновационного развития важны и спрос на новые разработки со стороны бизнеса, и их предложение, в том числе со стороны науки. В настоящее время в России есть проблемы и с тем, и с другим. Большинство компаний недостаточно заинтересованы в инновациях по причине слабой конкурентной среды, недостаточной вовлеченности в экспортные цепочки, высокой стоимости кредитных ресурсов, длительных сроков окупаемости инвестиций, короткого горизонта планирования. Как следствие, инновации не становятся значимым фактором конкурентоспособности для большинства предприятий, приоритетом их стратегий. Но и российская наука пока по большей части не готова эффективно взаимодействовать с бизнесом, выступать активным игроком на рынке технологий и интеллектуальных услуг.[2]

Анализ развития науки, образования и инноваций за последние двадцать лет выявил значительные проблемы в этих сферах.

Рис. 1 иллюстрирует динамику числа организаций, выполнявших научные исследования и разработки по Российской Федерации за 18 лет, и показывает, что она не равномерна, достигнув минимума в 2010 году -3492 организации, в

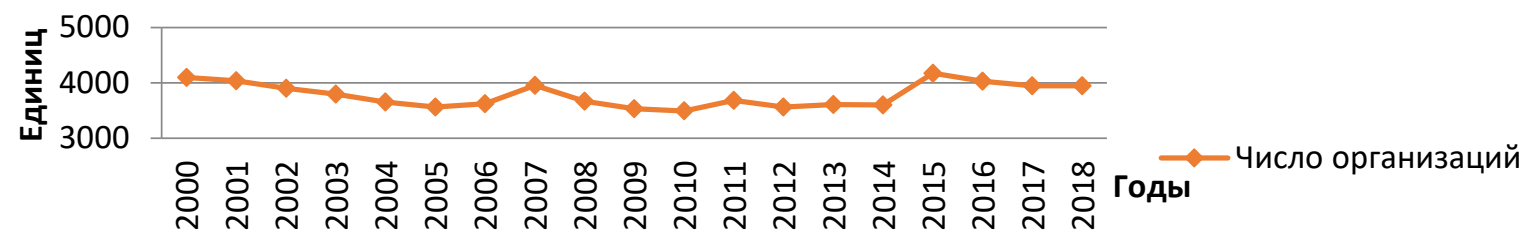

Рисунок 1. Число организаций, выполнявших научные исследования и разработки, по типам организаций по Российской Федерации 
2018 году число организаций возрастает до 3950, приближаясь к максимальной цифре 2000 года 4099 организаций.

Учитывая, что число и состав организаций, выполнявших исследования и разработки за неполные двадцать лет практически не изменился, необходимо отметить, что в его структуре произошли значительные изменения, таб. 1.

За прошедшее время снизилось количество научно-исследовательских организаций на $40 \%$, однако рост данного показателя в секторе высшего образования почти в 2,5 раза отражает, что частично функцию, которую реализовывали научные организации, взяли на себя исследователи, работающие в сфере высшего образования. Положительная динамика научноисследовательских, проектно-конструкторских подразделений в промышленности дает основания предположить, что и эти предприятия, в какой-то мере, берут на себя исследовательскую функцию, поскольку необходимость в научных исследованиях на предприятиях сохраняется. Таким образом, видна тенденция перераспределения научных исследований из научноисследовательских организаций в другие формы организации науки.

Финансирование науки из средств федерального бюджета представлено на рис. 2. Расходы на гражданскую науку выросли в 24 раза за исследуемый период, составив к расходам федерального бюджета 2,52\% в 2018 году (для сравнения 1,69\% в 2000 г.). За последний год, тридцать пять процентов из этой суммы составляют расходы на фундаментальные исследования, 65 процентов на прикладные. Соотношение финансирования фундаментальных и прикладных исследований за прошедшее время менялось, но расходы на науку из года в год - росли.

Численность персонала, занятого научными исследованиями и разработками по РФ, рис. 3, снижается за исследуемый период на 23\%. Структура исследователей по областям науки практически не меняется: большая часть - около 60 процентов приходится на технические науки; приблизительно - 25 процентов на естественные, медицинские, сельскохозяйственные науки; общественные и гуманитарные науки занимают в среднем от 3 до 5 процентов. Численность исследователей, имеющих ученую степень, сократилась с 105911 человек в 2000 году до 100330 человек в 2018 г., что составляет около 6 процентов.

Таким образом, за последнее время происходит усиление роли ВУЗов в сфере научных исследований, при ослаблении значимости научных организаций, снижение численности персонала, занятого научными исследованиями и разработками, увеличение финансирования науки из средств федерального бюджета.

Проанализируем ситуацию за прошедшие двадцать лет в сфере образования. На рис. 4, 5 видно, что в системе подготовки научных кадров ситуация ухудшается, в последнее время происходит резкое сокращение подготовки докторантов и аспирантов.

За период 2010-2019 гг. число докторантов резко падает (происходит снижение на 70\%), количество человек защитивших докторскую диссертацию уменьшается на $75 \%$.

Немного лучше ситуация с выпуском из аспирантуры, но и здесь идет значительный спад. Практически на 55\% снижается за исследуемый период численность аспирантов, количество человек защитивших кандидатскую диссертацию - на $83 \%$.

Таблица 1. Структура организаций, выполнявших научные исследования и разработки, по типам организаций по Российской Федерации, в процентах

\begin{tabular}{|c|c|c|c|c|c|}
\hline & \multicolumn{5}{|c|}{ Годы } \\
\hline & 2000 & 2005 & 2010 & 2015 & 2018 \\
\hline научно-исследовательские организации & 66 & 59 & 53 & 41 & 40 \\
\hline конструкторские организации & 8 & 14 & 10 & 8 & 6 \\
\hline проектные и проектно-изыскательские организации & 2 & 2 & 1 & 1 & 1 \\
\hline опытные заводы & 1 & 1 & 1 & 1 & 1 \\
\hline образовательные организации высшего образования & 10 & 11 & 15 & 25 & 23 \\
\hline $\begin{array}{l}\text { организации промышленности, имевшие научно- } \\
\text { исследовательские, проектно-конструкторские } \\
\text { подразделения }\end{array}$ & 6 & 6 & 7 & 9 & 11 \\
\hline прочие & 7 & 7 & 13 & 15 & 18 \\
\hline Итого & 100 & 100 & 100 & 100 & 100 \\
\hline
\end{tabular}




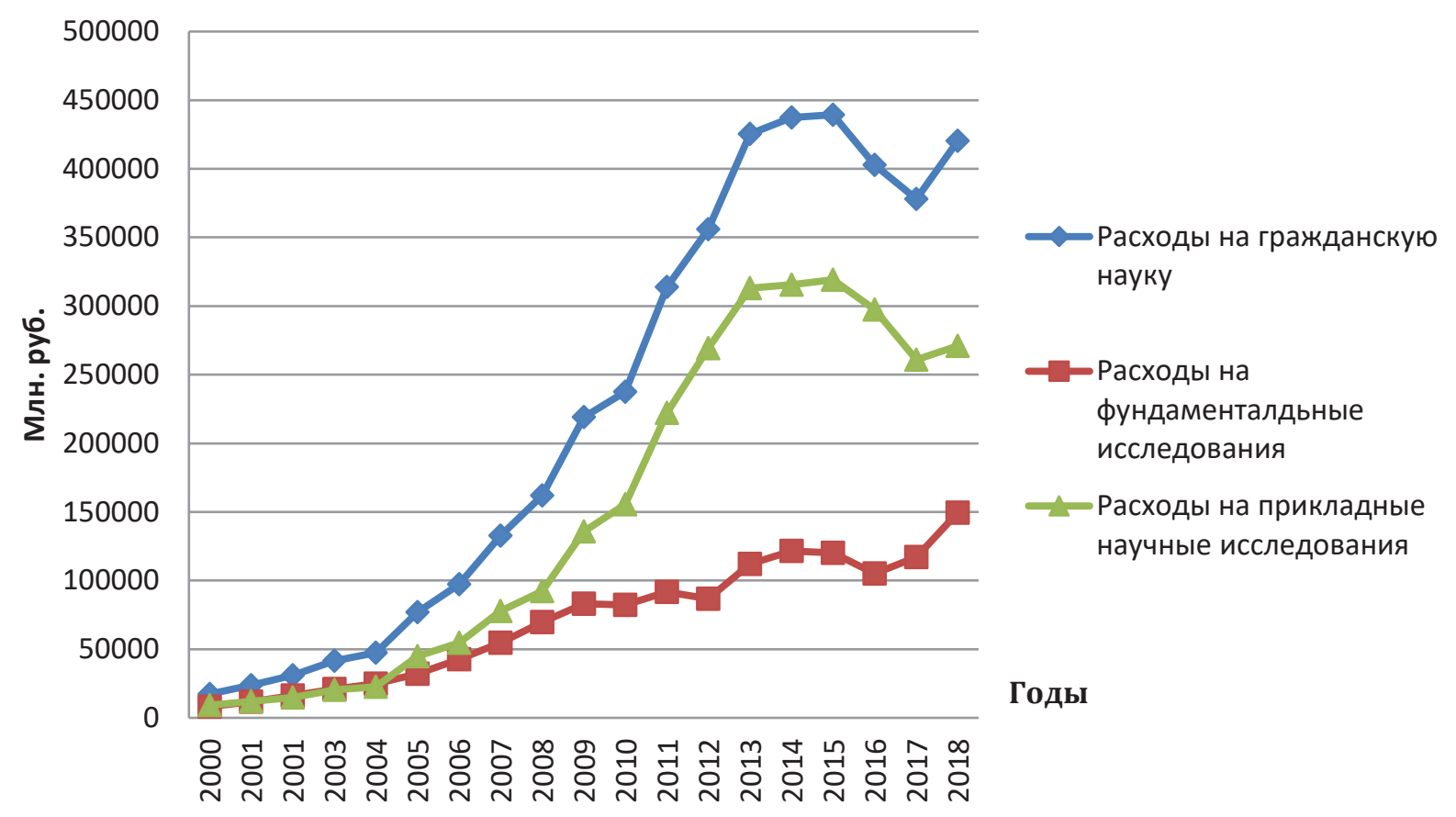

Рисунок 2. Финансирование науки из средств федерального бюджета

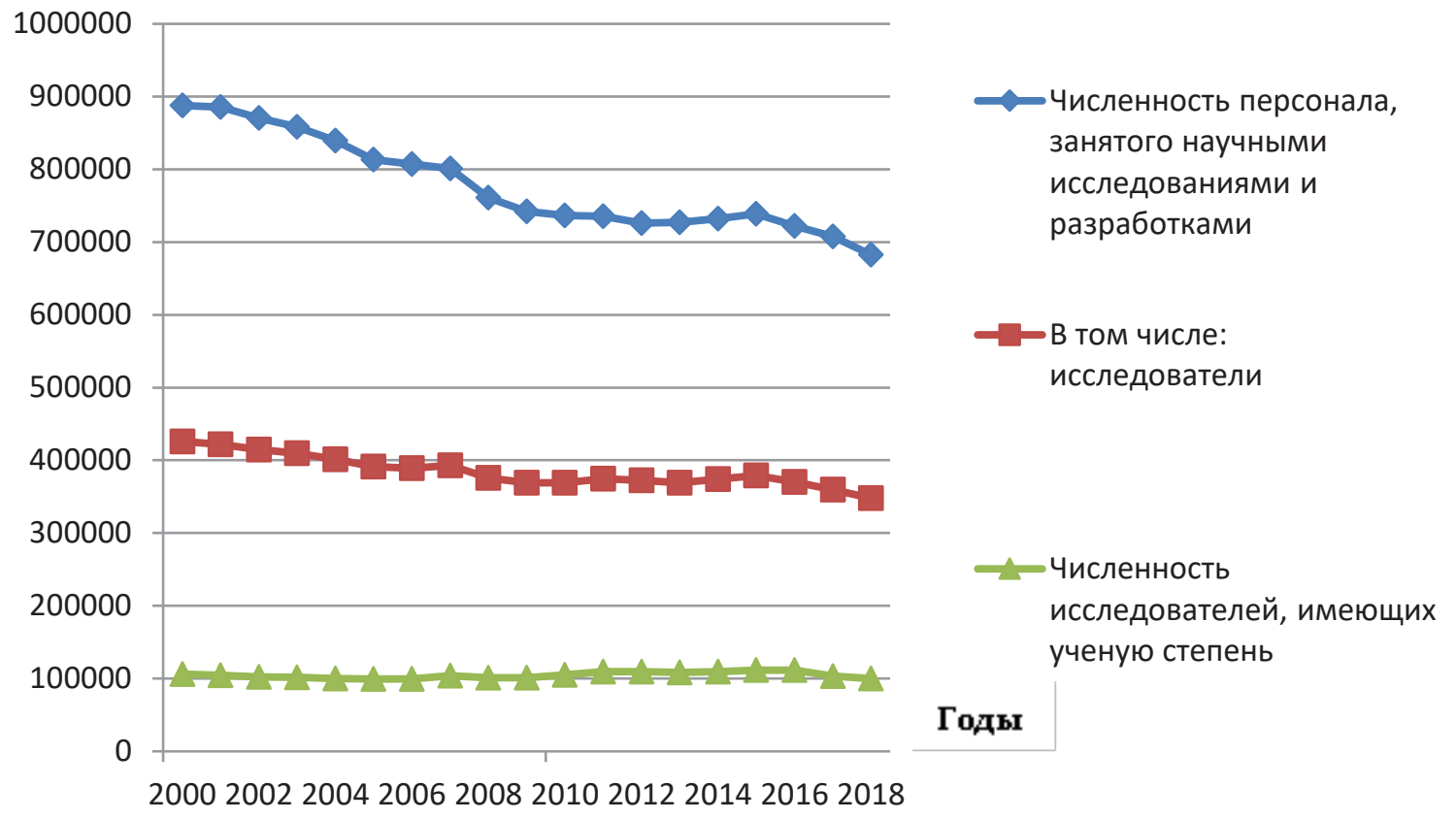

Рисунок 3. Численность персонала, занятого научными исследованиями и разработками по РФ 


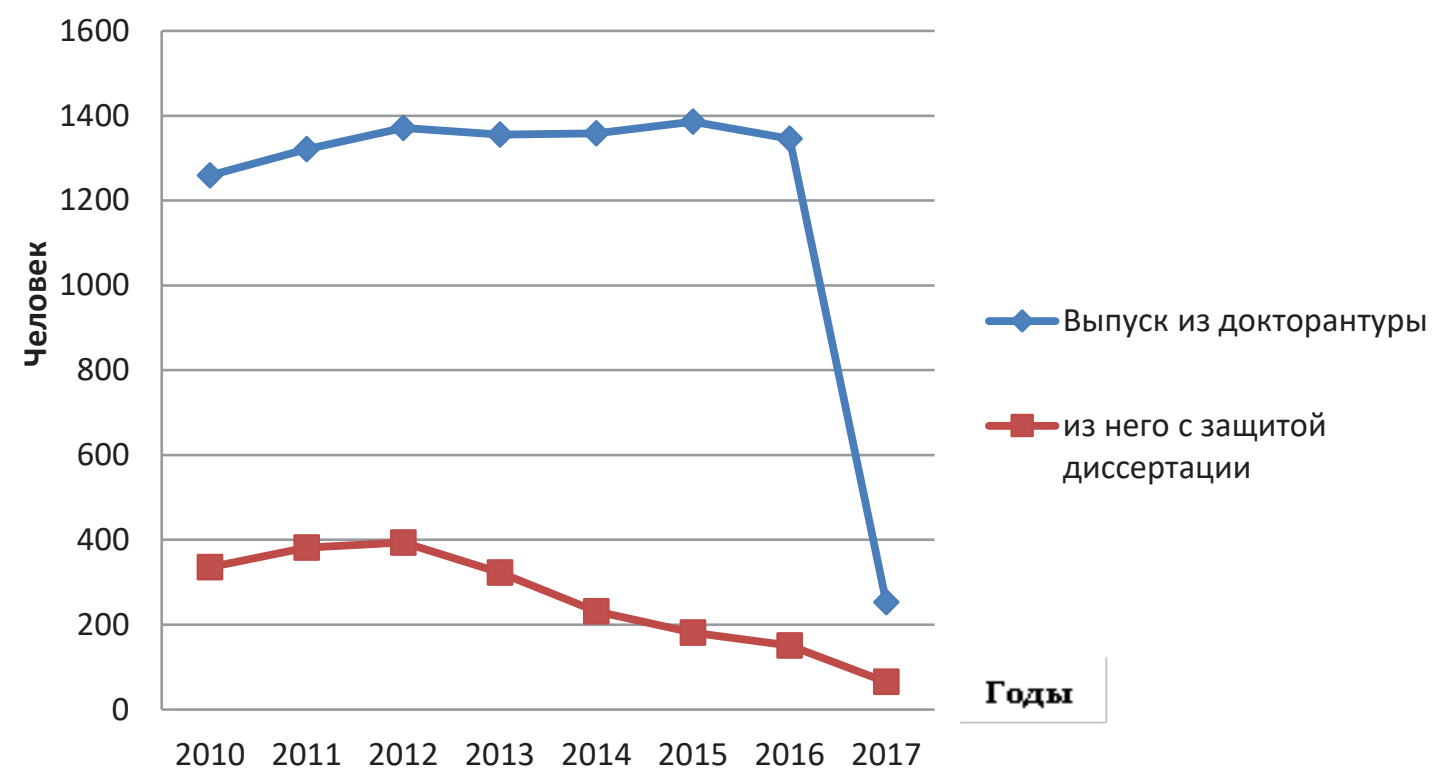

Рисунок 4. Выпуск из докторантуры

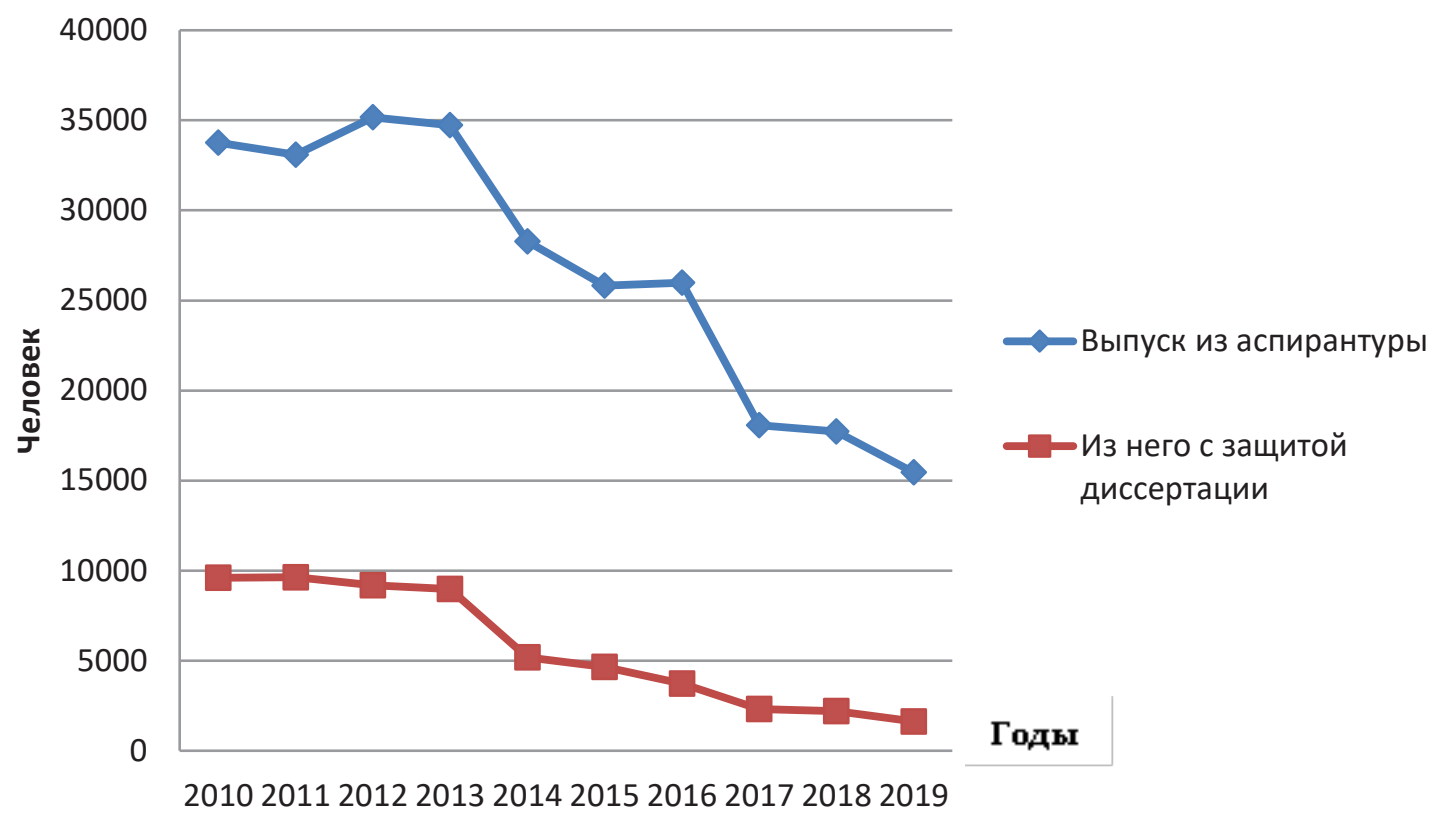

Рисунок 5. Выпуск из аспирантуры 
Таблица 2. Численность студентов, обучающихся по образовательным программам высшего образования - программам бакалавриата, специалитета, магистратуры, на 10000 человек населения, человек

\begin{tabular}{|c|c|c|c|c|c|}
\hline & 2000 & 2008 & 2010 & 2015 & 2019 \\
\hline Российская Федерация & 324 & 526 & 493 & 325 & 277 \\
\hline
\end{tabular}

Отрицательная тенденция сохраняется и на уровне высшего образования. Численность студентов, обучающихся по образовательным программам высшего образования - программам бакалавриата, специалитета, магистратуры, на 10000 человек населения за неполные двадцать лет имела неравномерную динамику: достигнув пика в 2008 году - 526 человек, она снижается к 2019 году до 277 человек, т.е. за все время исследования падает на 15\%, табл. 2 .

Полный цикл получения образования в высшей школе включается в себя несколько ступеней: бакалавриат и магистратуру. Потом начинается послевузовская подготовка (аспирантура и докторантура). Тенденция последних лет показывает, что значительная часть специалистов заканчивает обучение на одной из промежуточных стадий, в силу разных обстоятельств не считая необходимым проходить полный цикл образования.

Анализ тенденций в сфере инноваций за прошедшее время показывает, что затраты на инновационную деятельность за неполные десять лет выросли почти в пять раз (табл. 3). Однако, не смотря на это, удельный вес инновационных товаров, работ, услуг в общем объеме отгруженных товаров, выполненных работ, услуг неравномерен, максимальных значений достигает в 2015 году, затем, вновь снижается, всего на 10 процентов превышая уровень 2010 года.

Положительную динамику демонстрируют показатели таб. 4. На протяжении почти пятнадцать лет значительно увеличивается в РФ использование объектов интеллектуальной собственности.

Одним из основных факторов и условий создания инноваций является развитие и накопление научных знаний, которые в свою очередь формируются учеными, многие из которых имеют степени кандидата или доктора наук. И развитие науки, и производство инноваций базируются на образовании. Поэтому, необходимо обратить внимание на процессы, происходящие в этих сферах и решить ряд проблем, видимых уже на современном этапе развития.

1) Для вузов инновационными продуктами являются выпускники со сформированными требуемыми компетенциями. И дополнительная нагрузка на преподавателей в рамках проведения научных исследований отвлекает их от основной деятельности.

2) Быстрое устаревание знаний, препода-

Таблица 3. Основные показатели инновационной деятельности

\begin{tabular}{|l|c|c|c|c|}
\hline & $\begin{array}{c}\text { Единица } \\
\text { измерения }\end{array}$ & 2010 & 2015 & 2019 \\
\hline $\begin{array}{l}\text { Удельный вес инновационных товаров, работ, услуг в общем } \\
\text { объеме отгруженных товаров, выполненных работ, услуг }\end{array}$ & процент & 4.8 & 8.4 & 5.3 \\
\hline Затраты на инновационную деятельность & мрд. руб. & 400,8 & 1200,3 & 1954,1 \\
\hline $\begin{array}{l}\text { Удельный вес затрат на технологические инновации в общем } \\
\text { объеме отгруженных товаров, выполненных работ, услуг }\end{array}$ & процент & 1.6 & 2.6 & 2.1 \\
\hline
\end{tabular}

Таблица 4. Сведения об использовании объектов интеллектуальной собственности по Российской Федерации, единиц

\begin{tabular}{|l|c|c|c|c|}
\hline \multicolumn{1}{|c|}{ Вид интеллектуальной собственности } & 2005 & 2010 & 2015 & 2019 \\
\hline Изобретения & 8530 & 10663 & 14181 & 20402 \\
\hline Полезные модели & 2815 & 4188 & 5556 & 7166 \\
\hline Промышленные образцы & 1181 & 1560 & 1659 & 2466 \\
\hline Базы данных & 121 & 273 & 1153 & 1961 \\
\hline Программы для ЭВМ & 818 & 2861 & 6459 & 14694 \\
\hline Топологии интегральных микросхем & 27 & 56 & 135 & 549 \\
\hline
\end{tabular}


ваемых в ВУЗах в параллели с интенсивной информатизацией общества и переходом к значимой роли цифрового образования.

3) Несоответствие принятых учебных стандартов интересам и способностям обучающихся;

4) Конфликт сторонников концепций узкой специализации и многостороннего развития.

5) Научный рынок труда в России характеризуется высокой долей концентрации в нескольких регионах (в первую очередь г. Москва и Московская область), крайне слабой представленностью частного сектора, незначительной академической мобильностью и низким уровнем зарплат научных сотрудников.

Таким образом, на современном этапе развития ключевыми становятся организации, производящие новые знания, основанные на исследованиях и разработках, распространяющие их и ищущие пути их использования (коммерциализации) на практике. Следует отметить, что в экономике, основанной на знаниях, доля труда, связанная собственно с производством конечного продукта, существенно сокращается. Но в его окончательную стоимость значительно больший вклад вносит труд на стадиях разработки, создания образца, его испытаний и выведения на рынок, а также на последующих этапах доведения продукта до потребителя и его обслуживания в течение жизненного цикла [3]. В этом процессе используется сложный, интеллектуальный труд, предполагающий высокий уровень знаний и интенсивность их использования. Поэтому эффективная, слаженная работа цепочки «образование-наука-инновации» - это один из инструментов экономического роста экономики в целом.

\section{Библиографический список}

1. Лютикова О.А. Условия развития и закономерности инновационной экономики / О.А. Лютикова, Г.А. Рыбина, Т. А. Сысоева // Экономика и предпринимательство. - 2020. - № 9(122). - С. 160-166.

2. Батенева T. Рейтинг на вырост // Российская газета, Фармацевтика. - № 120 (7878). - 05.06.2019. - https:// izak.ru/upload/medialibrary/339/Фармацевтика\%2005062019.pdf (дата обращения 05.09.2020).

3. Кочетков Г.Б. США: новая роль университетов в экономике, основанной на знаниях //США и Канада: экономика, политика, культура. - 2007. - № 7(451). - С. 3-20.

4. Викулов С. Ф. Актуальные проблемы науки и образования в контексте инновационной парадигмы / С. Ф. Викулов, Т. А. Югай // Вооружение и экономика. - 2013. - № 2(23). - С 52-60.

5. Ульянова И.В. Проблема синтеза инноваций и реноваций в российской системе образования XXI века // Современные проблемы науки и образования. - 2019. - № 3. - URL: http://science-education.ru/ru/article/ view?id=28857 (дата обращения: 17.09.2020).

6. https://rosstat.gov.ru/ (дата обращения: 30.08.2020) 